\title{
The Administration Model Complexity of School Under the Secondary Educational Service Area Office
}

\author{
Phramaha Santichai Abhisanti (Phonsrisom) ${ }^{1}$, Somsak Boonpoo², Rawing Ruangsanka ${ }^{3},{ }^{4}$ Veerapan \\ Pongvatnanusorn \\ ${ }^{1,2,3,4}$ Faculty of Education, Mahachulalongkornrajavidyalaya University, \\ ${ }^{5}$ Pattani Buddhist College, Mahachulalongkornrajavidyalaya University \\ 12aphisanti1991@gmail.com, ${ }^{2}$ boonpoo999@hotmail.com, ${ }^{3}$ billionwings@ hotmail.com, ${ }^{4}$ veerapanpong@yahoo.com
}

\begin{abstract}
The purposes of this research were 1) to study the state of problem in complex administration of School Under the Secondary Educational Service Area Office, 2) to develop and propose the administration model complexity of school under the Secondary Educational Service Area Office. Mixed methods research was used for research design. In qualitative research was conducted by using documentary study, in-depth interview with 5 key informants and focus group discussion with 9 experts. Research tools were documentary record form and interview form. In quantitative research, 400 samples of secondary school administrators and teachers were used for data collection and was selected by multistage random sampling. Research tool was questionnaires. Qualitative data was analyzed by content analysis whereas quantitative data were analyzed by percentage, frequency, mean, and standard deviation. Results indicated that 1) the state of problem in complex administration of School Under the Secondary Educational Service Area Office consisted of 4 aspects and overall has shown the balanced level of complexity that was the problem solving consisted of (1) to encourage community to have strong academic administration in academic management, (2) to set up fund raising of resources to support education in financial management, (3) to set human resource planning for educational personnel in human management, and (4) to conduct research for policy and plan development in general administration. 2) The administration model complexity of school under the Secondary Educational Service Area Office consisted of 5 components which were (1) the principle of complexity, (2) the objective of complex administration, (3) process of complex administration, (4) model utilization, and (5) key success factors. Results of validation based on 4 standards in overall was at high level.
\end{abstract}

Index Terms

Administration Model Complexity, Complex Administration, Secondary Educational Service Area Office

Article Received: 10 August 2020, Revised: 25 October 2020, Accepted: 18 November 2020

\section{Introduction}

All aspects of the current day have reflected the common awareness of human beings that all things are complex and that they are even more complex. In an age when society is able to connect information, knowledge, ideas, values, behaviors with online communication [1]. Stephen Hawking, the great scientist of the world today, said, "This century is the greatest scientist of the world, century of complexity." Therefore, whether we care or not, the complexity of things connected with each other continues. Only if we can understand this complexity, we will manage our lives and society properly and sustain our ecosystems. If compared to the Buddhist beliefs that Thai people are familiar with then the correct understanding of complexity is to have righteousness or right opinion, which is the first priority of Makkā 8, which begins with attitude that is to see the truth first, then will think or act other things correctly followed by [2] a study by the United States International Development Organization (USAID) found that the loss of teacher time from the classroom is one of the key factors that directly affect the quality of learners' learning. The study of teachers' time spent in classrooms in 2012 in five countries was Ethiopia, the Republic of Kauatema, Honduras, Mozambique and Nepal. It was found that when teachers were pulled outside of the classroom unrelated teaching is more than 20-30 percent of the total teaching time. It will greatly affect the learning of learners (Kaisaphatrao, 2015). In addition, the Office of Social
Promotion of Learning and Youth Quality (SSC) has surveyed the life schedule of Thai teachers in 1 year. It was found that Thai teachers were drawn from their teaching duties to do other activities that is not involved in teaching until it affects students by conducting a survey of 427 teachers who received "the Good Teachers Award" from August 15 - October 15, 2014, it was found that in 1 year with the total number of open classes 200 days, teachers had to spend time outside activities classes that were not organized on weekdays were 84 days, accounting for $42 \%$ of the time which is considered a very high number, with the non-teaching classes that teachers have to spend the most time in the top 3, on average, namely No. 1, external organization assessment for 43 days, No. 2, academic competition for 29 days, No. 3 for 10 days of training from outside agencies. The major problems of teacher quality are lack of knowledge and ability. Teaching skills sufficient to pass on to learners including the lack of awareness of their duties and responsibilities. Some teachers spend their time teaching private activities such as supplementing their work, and doing work to promote degrees. It is one of the reasons why teachers have to leave the classroom. Such problems, although they are problems that arise from the teachers themselves, greatly affect the learning achievement and the quality of education [3]. The major problems that become obstructions in teacher performance are: 1) heavy burden, other than teaching $22.93 \%$, 2) the number of teachers is not enough, and teaching does not match the qualifications $18.57 \%$, 3) lack of ICT skills $16.8 \%$, 4) new generation 
teachers lack spirit while older teachers did not adapt $16.49 \%$, 5) heavy teachers resulted in children studying $14.33 \%$ more, and 6) lack of freedom in teaching and learning $10.88 \%$ [4]. The researcher is interested in studying and researching management model of complexity of schools Office of the Secondary Educational Service Area to serve as a guideline for agencies involved in the development of Thai people in the 4.0 era and as a guideline for applying to other departments for the school director and teacher or the person who can apply training to increase administrative skills complexity management to increase efficiency and effectiveness in teaching and learning management make students to have better learning skills and can continue to be a good youth of the nation.

\section{Research Objectives}

The purposes of this research were 1) to study the state of problem in complex administration of school under the Secondary Educational Service Area Office, 2) to develop and propose the administration model complexity of school under the Secondary Educational Service Area Office.

\section{Research Methods}

\section{A. Research Design}

Mixed methods research was used for research design. Qualitative research was conducted by using documentary study, in-depth interview with 5 key informants and focus group discussion with 9 experts. Research tools were documentary record form and interview form. In quantitative research, 400 samples of secondary school administrators and teachers were used for data collection and was selected by multistage random sampling. Research tool was questionnaires. Qualitative data was analyzed by content analysis whereas quantitative data were analyzed by percentage, frequency, mean, and standard deviation.

\section{B. Research Process}

The researcher has set all 3 research steps as follows: 1) study problems in educational institutes of School under the Secondary Educational Service Area Office, 2) develop a model for the complexity administration of educational of School under the Secondary Educational Service Area Office, and 3) propose the model for the complexity management of the school Office of the Secondary Educational Service Area.

Step 1: Study the problem of educational institutions under the Secondary Education Service Area Office, there are 3 steps: 1) Study from documents, 2) Study from distribution of questionnaires about problems of educational institutes under Secondary Educational Service Area Offices, and 3) study by interview about the problem of educational institutions under the Secondary Educational Service Area Office.

Step 2: Develop a model for the complexity management of the school under the Secondary Educational Service Area Office has 2 steps as follows: 1) Drafting a model for the complexity management of the school Secondary Education Area Office, 2) Develop a model for the complexity management of educational institutions. Office of the Secondary Educational Service Area by focus group discussion.

Step 3: Propose the administration model complexity of school under the Secondary Educational Service Area Office as the following steps to revise, improve and propose the administration model complexity of the school Office of the Secondary Educational Service Area Office.

\section{Results}

The results of the research showed that:

1. the state of problem in complex administration of School Under the Secondary Educational Service Area Office indicated that the scope of the school administration in all four departments, overall, is at a moderate level. When considering each side, academic administration with the highest average moderate, personnel management general management, and budget management with a medium low average. When considered on a case-by-case basis, the priority of the complexity management under the Secondary Education Service Area Office. In terms of academic administration, there is an encouragement for the people to have academic strength. In terms of budget management, there is resource mobilization and investment for education. Personnel management work is the allocation of the force of government teachers and educational personnel. In general management, there is research to develop policies and plans. 2. Develop the administration model complexity of school under the Secondary Educational Service Area Office, there are 5 components under the Secondary Education Service Area Office: (1) the principle of complexity, (2) the objective of complex administration, (3) process of complex administration, (4) model utilization, and (5) key success factors [5]. Results of the audit and present the model for the management of the complexity of the school under the Office of the Secondary Educational Service Area conducted the inspection of the four aspects, the overall level was at a high level. when considering each side. The side with the highest average was at the highest level, it was useful, accuracy, and at a large level, including suitability and the possibilities, respectively.

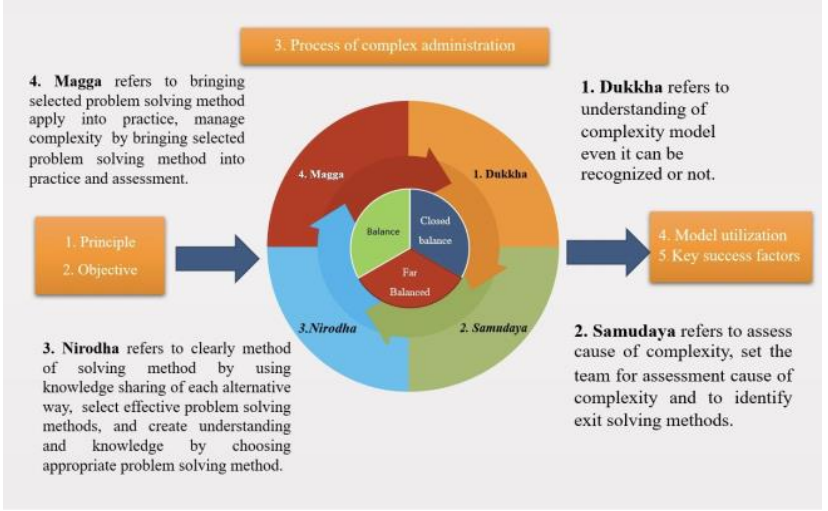

Fig.1 Process of Complex Administration

From Fig.1 Process of complex administration can be shown as the following detail:

The administration model complexity of school under the Secondary Educational Service Area Office consisted of 5 components which were (1) the principle of complexity, (2) 
the objective of complex administration, (3) process of complex administration, (4) model utilization, and (5) key success factors. Buddhist principle of four noble truths was integrated for complex administration and details were shown as below items.

1. Dukkha refers to understanding of complexity model even it can be recognized or not.

2. Samudaya refers to assess cause of complexity, set the team for assessment cause of complexity and to identify exit solving methods.

3. Nirodha refers to clearly method of solving method by using knowledge sharing of each alternative way, select effective problem-solving methods, and create understanding and knowledge by choosing appropriate problem-solving method.

4. Magga refers to bringing selected problem-solving method apply into practice, manage complexity by bringing selected problem solving method into practice and assessment.

Process of complex administration by nature of complexity, equilibrium has the following steps:

1) Suffering (Dukkha) is to understand the form of complexity. Whether the complexity is perceived or not.

1.1 Set up a committee to understand the complexity.

1.2 Study the scope of the management of all 4 departments.

1.3 Summary of management results of all 4 departments.

2) Samudaya is to examine the cause of the complexity. Arrange a team to investigate the reasons for the complexity and identify the solutions to the existing problems.

2.1 Set up a committee

2.2 Brainstorm

2.3 Summarize the cause of the complexity problem.

3) Nirodha refers being angry is to make the solution to the problem clear by exchanging opinions on each option select effective solutions build understanding and knowledge by choosing an appropriate solution.

3.1 Set up a committee

3.2 Brainstorm

3.3 Check to see if there has ever been a problem with this complexity or not in order to see solutions to improve problems.

3.4 Analyze the risks that will result in the solution being successful or failing.

4) Magga is to implement a solution to a selected problem, and manage complexity by implementing and evaluating the chosen solution.

Near equilibrium has the following steps

1) Suffering (Dukkha) is to understand the form of complexity. Whether the complexity is perceived or not.

1.1 Set up a committee to understand the complexity.

1.2 Study the scope of the management of all 4 departments.

1.3 Summary of management results of all 4 departments

2) Samudaya is to examine the cause of the complexity. Arrange a team to investigate the reasons for the complexity and identify the solutions to the existing problems.

2.1 Set up a committee

2.2 Brainstorm

2.3 Summarize the cause of the complexity problem.

3) Nirodha refers being angry is to make the solution to the problem clear by exchanging opinions on each option Select effective solutions, to build understanding and knowledge by choosing an appropriate solution.

\subsection{Set up a committee}

3.2 Brainstorm

3.3 Check to see if there has ever been a problem with this complexity or not. In order to see solutions to improve problems.

3.4 Analyze the risks that will result in the solution being successful or failing.

4) Magga is to quickly implement a solution to the selected problem. Manage complexity by implementing and evaluating the chosen solution. Because if the delay will affect other work involved.

Far-equilibrium has the following steps

1) Suffering is to understand the form of complexity. Whether the complexity is perceived or not.

1.1 Set up a committee to understand the complexity.

1.2 Study the scope of the management of all 4 departments.

1.3 Summary of management results of all 4 departments

2) Samudaya is to examine the cause of the complexity. Arrange a team to investigate the reasons for the complexity and identify the solutions to the existing problems.

2.1 Set up a committee

2.2 Brainstorm

2.3 Summarize the cause of the complexity problem.

3) Nirodha refers being angry is to make the solution to the problem clear by exchanging opinions on each option select effective solutions build understanding and knowledge by choosing an appropriate solution.

3.1 Set up a committee

3.2 Brainstorm

3.3 Check to see if there has ever been a problem with this complexity or not. In order to see solutions to improve problems.

3.4 Analyze the risks that will result in the solution being successful or failing.

4) Magga is to quickly implement a solution to the selected problem. Manage complexity by implementing and evaluating the chosen solution because if the delay will have a big impact on the organization about the existence or collapse of the organization.

\section{Discussions}

From general information of teachers in educational institutions Under the Office of the Secondary Educational Service Area The respondents found that the number of female teachers, aged 41 years and above and having a master's degree. There are opinions that are consistent overall. That the state of the complex management problem of the school Office of the Secondary Educational Service Area In managing complexity from research Domestic research related to the complexity management of educational institutions Office of the Secondary Educational Service Area There were no studies that could directly compare with each other. But there is a similar study: research by Van Vianen, J., Reed, J., \& Sunderland studies matters from global complexity to local reality. The research results show that When adapting to the complexity of the problem Knowing how to fix it, it will be seen that the opportunity to deal with complex problems in order to reach the goals that the organization has set both inside and outside [6]. Operational problems according to the school operation planning process of the high school administrators 
and personnel in the planning department Under the Department of Education, Educational District 5, the research results showed that Small school planning personnel have more problems than medium and large school planning personnel [7] that align with the complexity management model of schools. Under the secondary education area office in the process of complexity management and administration of 4 departments.

The administration model complexity of school under the Secondary Educational Service Area Office has 5 components: (1) the principle of complexity, (2) the objective of complex administration, (3) process of complex administration, (4) model utilization, and (5) key success factors which is related to some issues with Pichet Phophak, mentioning the composition of the pattern has 3 parts: 1) Principle and Objectives 2) Structure and essence 3) Implementation and conditions for success.

Presentation of the model for managing the complexity of the school Under the Office of the Secondary Educational Service Area, the researcher examined the model by distributing questionnaires, revising and presenting the model. From examining the form of management of school complexity under the Office of the Secondary Educational Service Area, it was found that the model for the complexity management of the school under the Office of the Secondary Educational Service Area. The overall picture is at a high level. Usefulness at the greatest level showed that management model of complexity of schools Under the Office of the Secondary Educational Service Area. It is related to the 4 audit standards [9]: 1) utility, 2) feasibility, 3) suitability, and 4) accuracy. Therefore, it can be considered that management model of complexity of schools under the Office of the Secondary Educational Service Area that can be used to manage the complexity of the school under the Office of the Secondary Educational Service Area. The results from the examination of the five components of the pattern were (1) the principle of complexity, (2) the objective of complex administration, (3) process of complex administration, (4) model utilization, and (5) key success factors [10].

Principles of educational institution complexity management model, Office of the Secondary Educational Service Area. When considering each side, the side with the highest average at the highest level, it was useful, accuracy, suitability, and the areas with the lowest mean at the high level were probability.

Objectives of the school complex management model Office of the Secondary Educational Service Area When considering each side. The side with the highest average at the highest level, it was useful, accuracy side and to a large extent unitability and the areas with the lowest mean at the high level were probability

The complexity management process of the school complex management model. Office of the Secondary Educational Service Area. When considering each side, the side with the highest average at the highest level, it was useful accuracy and to a large extent suitability and the areas with the lowest average at the high level were probability.

Apply the pattern When considering each side The side with the highest average, and at the highest level, including accuracy usefulness possibility aspect and the areas with the lowest average at the high level were suitability.
Key success factors, when considering each side, the side with the highest average at the highest level, including accuracy usefulness unitability and the areas with the lowest average at the high level were probability.

\section{Recommendations}

\section{A. Recommendations for Practices}

From the research results, it was found that the examination of the school complex management model under the Office of the Secondary Educational Service Area. It was found that the model for the complexity management of the school under the Office of the Secondary Educational Service Area. The overall picture is at a high level. Usefulness at the greatest level showed that Management model of complexity of schools under the Office of the Secondary Educational Service Area. It is very useful for managing the complexity of the school. Under the Office of the Secondary Educational Service Area Should be set as a policy.

\section{B. Recommendations for Further Research}

1. In the context of educational institutions under the Office of the Secondary Education Service Area nationwide which vary according to the context. Therefore, research should be conducted to study the approach to implementing the complexity management model, and problem solving for students in educational institutions

2. Further research studies should be carried out by developing social skills indicators for teachers and students in educational institutions under the Secondary Education Service Area Office.

\section{Conclusion}

The administration model complexity of school under the Secondary Educational Service Area Office consisted of 5 parts which were (1) the principle of complexity, (2) the objective of complex administration, (3) process of complex administration, (4) model utilization, and (5) key success factors. It can be used to manage the complexity of the school under the Office of the Secondary Educational Service Area by applying according to the context of the school and cooperation of all parties

\section{References}

[1] [1][2] O. Ngamwittayaphong, N. Nontakit Noppakao, the complexity of development: basic knowledge for change Bangkok Printing press.

[2] [3] C. Thongying, Teacher Problems: Problems Pending for Reform, Office of the Secretariat of the House of Representatives, Tanmakhom, 2016. 
[3] [4] R. Jitrojanarak, Office of the Social Promotion of Learning and Youth Quality, opens six obstacles to work for Thai teachers. [Online], source: https://www.isranews.org/component/cont ent/article [4 Feb.2020]

[4] [5] Thidnakhammanee and others, patterns and tools for educational research, Bangkok: Chulalongkorn University Press, 2005.

[5] [6] V. Vianen, J., Reed, J., \& Sunderland, T. (Rep.), Center for International Forestry Research, 2015, Retrieved May 28, 2020, from www.jstor.org/ stable/resrep01981.

[6] [7] Samnitthonglim, Implementation problems according to the school operational planning process of the administrators and personnel of the Secondary School Planning Department, Under the Department of General Education, Education District 5, Bangkok: Thai Thesis Database, 2002.

[7] [8] P. Phophak, "Development of a corporate school administration model Affiliated with the Office of the Basic Education Commission", Ph.D. in Educational Administration, Chulalongkorn University, 2010.

[8] (9) Best W. Quoted in Boonchomsri Sasan, Preliminary Research, 5th edition, Bangkok: Suwiriyasarn Publication, 1992.

[9] [10] Boonchomsri Sa-san, Preliminary research, 5th edition, Bangkok: Suwiriyasarn Printing, 1992 